\title{
Dramaturgia performativa e produção de corporeidades nos trabalhos do La Carnicería Teatro
}

Performative dramaturgy and production of corporealities in the work of La Carnicería Teatro

\section{Camila Damasceno Matteo Bonfitto}

Camila Damasceno doutoranda do PPG em Artes da Cena da Unicamp Matteo Bonfitto Professor livre-docente do Departamento de Artes Cênicas da Unicamp

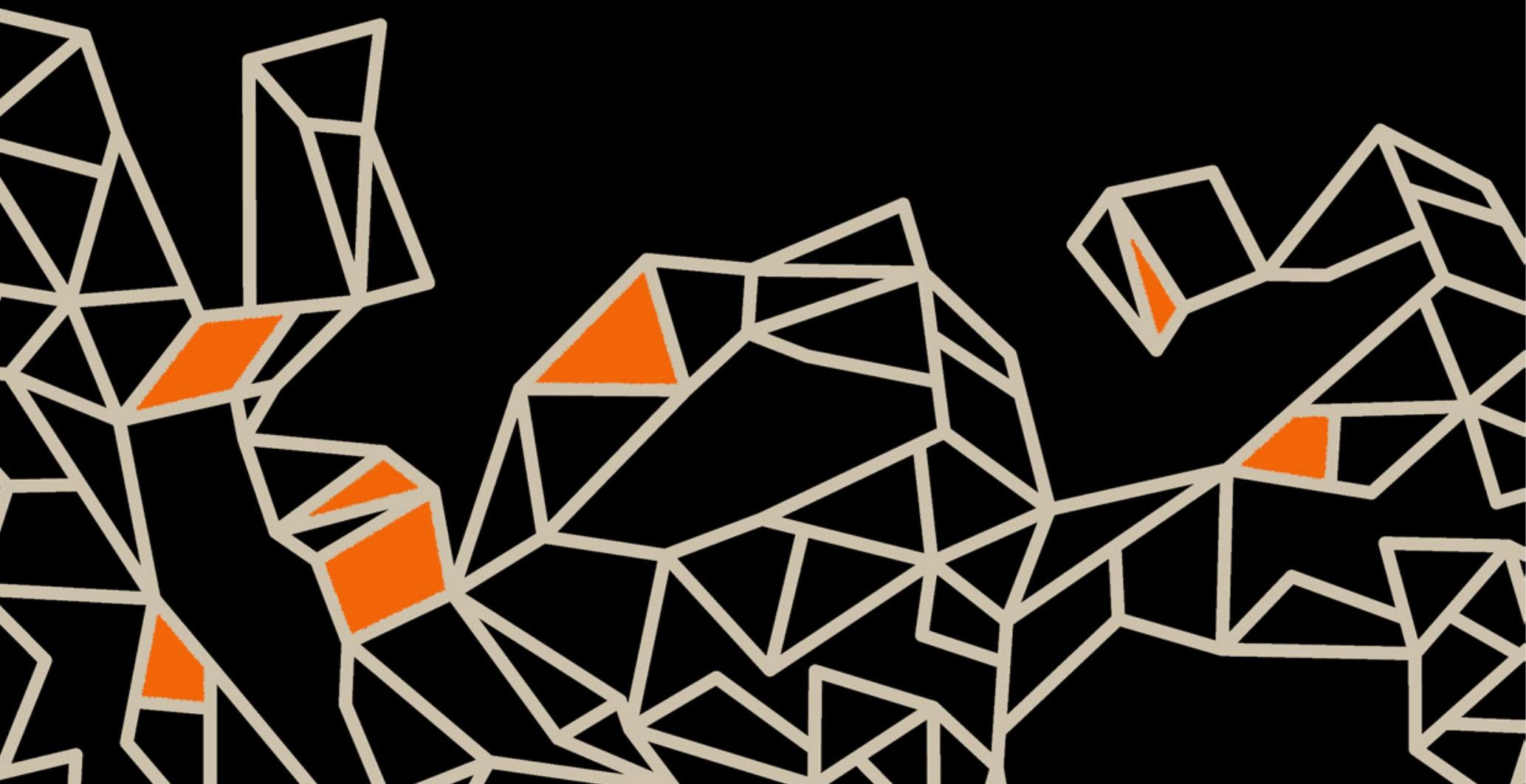




\section{Resumo}

O presente artigo foi elaborado como desdobramento das reflexões a respeito da relação entre criação dramatúrgica performativa e produção de corporeidades no trabalho do grupo espanhol La Carnicería Teatro. A abordagem parte de uma visão fenomenológica e foca nas corporeidades presentes na cena, que se constrói como sistema de tensões e instabilidades a partir das friç̧ões entre materialidades e discursos, gerando uma multiestabilidade perceptiva tanto nos atuantes quanto no público.

Palavras-chave: Dramaturgia Performativa, Corporeidade, La Carnicería Teatro, Performatividade, Rodrigo García.

\section{Abstract}

This article was elaborated as a deployment of reflections about the relationship between performative dramaturgy creation and production of corporeality in the work of the Spanish group La Carnicería Teatro. The approach is developed from a phenomenological view and focuses on the corporeality present in the scene, which is constructed as a system of tensions and instabilities from the frictions between materiality and discourses, generating perceptual multistability both in actors and in public. Keywords: Performative Dramaturgy, Corporeality, La Carnicería Teatro, Performativity, Rodrigo García.

À frente do grupo espanhol La Carnicería Teatro desde meados dos anos 1980, Rodrigo García (dramaturgo e encenador) propõe um processo de trabalho no qual a construção dramatúrgica ocorre concomitantemente à criação cênica, em um fluxo contínuo de produção tanto de materiais textuais, como sonoros, audiovisuais, cenográficos etc. Ainda que sejam autônomos, sem necessidade de complementação na cena para que gerem sentidos múltiplos, os textos dramatúrgicos de García não dão conta - nem se propõem a dar - do todo de suas obras, pois a dimensão semântica não é o único nem o principal aspecto comunicativo delas. Existe no trabalho do Carnicería um aspecto não semântico, um dado de percepção, que não é apreendido pela criação literária e que se potencializa justo na fricção entre as camadas de sentido e de presença, entre materialidades e discursos, gerando uma cena 
que se constrói como sistema de tensões e instabilidades capaz de proporcionar uma multiestabilidade perceptiva tanto nos atuantes quanto no público.

Com fortes referências autobiográficas, os textos já expõem um embate entre ficção e realidade. $O$ que García propõe é que sejam ditos, a partir de um repertório do ator como pessoa, com suas contradições, crenças e visões de mundo anteriores à construção da obra. A proposta é não se apoiar na criação de um ser ficcional/personagem que possibilite o deslocamento do que pensa e sente $o$ ator/a atriz em prol de um ser imaginário, de uma representação - "[...] não são personagens, senão pessoas" (GARCIA, 2013). Nesse aspecto, Rodrigo García assume uma postura semelhante à ideia de Tadeusz Kantor de "zona de pré-existência" do ator.

No texto "O teatro-happening", Kantor discorre sobre o que chama de "método da arte de ser ator". Suas reflexões a partir do trabalho com o Teatro Cricot $^{2}$ apresentam o que o encenador polonês percebeu como "predisposições elementares" do ator: individuais, específicas e "primeiras", algo que preexiste ao trabalho cênico e que diz respeito ao repertório prévio de cada um. Seriam estas pré-disposições elementares o motor de uma qualidade de real na cena do grupo. Para Kantor, a realidade reivindicada pelo texto não deveria ser representada de forma fácil e superficial, mas amalgamada, unida indivisivelmente a esta pré-existência do ator e da cena, "que se enraíze e surja" (KANTOR, 2008). Para tanto, defende, então, o desenvolvimento de um "espírito de equipe" que, associado à consideração de tais "predisposições preliminares", fomenta a autonomia da criação artística e o estabelecimento de uma "zona livre da arte do ator".

Em entrevista na MITsp (Mostra Internacional de Teatro de São Paulo), em 2014, Rodrigo García diz que o trabalho com os atores, que chama de "companheiros de uma viagem intelectual e cotidiana", é sempre o ponto de partida para suas criações e define a cumplicidade que se estabelece entre eles como fator mais importante no processo. "Só posso pedir [essa cumplicidade] a determinadas pessoas porque compartilham comigo certa filosofia que vai muito além do teatro" (GARCíA, 2014, tradução dos autores).

A preocupação primeira em estabelecer o que Kantor trata como "espírito de equipe," afeta diretamente o trabalho de García tanto enquanto encenador quanto dramaturgo. Na proposição de uma forma de trabalho na qual prevaleça 
esse espírito - fomentado por uma não hierarquização de funções ou saberes -, proporcionando a autonomia dos artistas envolvidos e a liberdade criativa de cada componente do grupo, o dramaturgo insere-se no processo de construção da obra de forma ativa e presente. Em entrevista publicada no catálogo de Gólgota Picnic, produzido pelo Centro Dramático Nacional de Madrid, em 2010, García revela sua reflexão sobre os processos de criação do grupo.

No início, há mais de quinze anos, seguia um processo normal, como qualquer dramaturgo; escrevia as obras e depois as montava. Depois fui mudando a metodologia do trabalho. Existe uma grande diferença entre o escrito e o que se escuta; o texto em cena geralmente é bastante frustrante, com muitas coisas que não funcionam. De fato, segundo o meu gosto, noventa por cento do teatro não funciona, são coisas que não compreendo, anacrônicas, como uma espécie de maquinaria que não anda. Eu me questionei sobre essas coisas e pensei que era melhor fazer desde dentro, desde o teatro, isso é, como se fosse uma obra arquitetônica na qual juntamos várias pessoas, vamos gerando materiais e vemos se aquilo é consistente para que as ideias tenham sua própria existência. Trata-se de materializar essas ideias, e a melhor forma de conseguir isso, já que trabalhamos com teatro, é estar junto a outras pessoas e ir construindo [...]. (CDN, 2010, p.9-10, tradução dos autores)

Essa noção de obra teatral como obra arquitetônica, na qual o dramaturgo/encenador lida com as materialidades cênicas para erguer o trabalho em conjunto com a presença essencial dos atores, é a base do processo de criação da companhia espanhola, embora, assim como Tadeusz Kantor, haja uma ressalva quanto ao aspecto improvisacional. Para o encenador polonês, o que chama "zona livre da arte do ator" não deve ser confundido com a improvisação, pois "as práticas e as atividades dos atores possuem a estrutura e a textura dos happenings. Elas abarcam toda realidade, as coisas, as situações e as pessoas" (KANTOR, 2008).

No trabalho do La Carnicería, esse aspecto improvisacional raramente está presente nas apresentações, mas é ponto de partida dos processos de criação. "Os ensaios nunca são uma repetição de coisas, mas momentos de criação. Cada ensaio é uma experiência, uma descoberta de materiais"', diz

1 John Romão em entrevista concedida à pesquisadora Camila Damasceno em 15 de março de 2014, em São Paulo, Brasil, e ainda não publicada. 
John Romão (assistente de direção), reforçando a descrição do processo feita por García. Para o dramaturgo/encenador, no entanto, é importante frisar que a estrutura das obras não deixa espaços para improvisação em cena: "É uma estrutura totalmente rígida, totalmente medida, que tem suas próprias leis muito calculadas" (DIAGO, 2002, p. 1, tradução dos autores). Dessa forma, a prática da improvisação nos trabalhos do grupo estaria mais próxima da ideia de improvisação enquanto método², explorada na geração de materiais e não a serviço dos mesmos. Um tipo de improvisação que se torna o meio através do qual os materiais são produzidos, gerando narrativas não lineares e diferentes tipos de seres ficcionais.

A improvisação enquanto método, nesse sentido, é um dos aspectos mais importantes dos processos de criação do Carnicería, considerado pelo dramaturgo e pelos atores como muito intuitiva, pela qual se experimentam muitas coisas sem a preocupação de seguir uma metodologia rígida. Os momentos de criação concentram-se principalmente no trabalho com as materialidades da cena. Os ensaios transcorrem a partir de proposições de García. Os estímulos partem de comandos que buscam ser claros e precisos, porém deixando brechas para a criação dos atores; comandos como: "pulem como jovens em shows de rock" ou "sapateie em cima da mesa." A cada dia se criam novas ações, imagens, movimentos sem que sejam repetidos até que o diretor proponha as primeiras possibilidades de ordenação dos fragmentos.

O trabalho constante com as materialidades cênicas também é parte importante nesse processo de criação improvisacional. Sons, objetos, figurinos vão sendo incorporados de forma quase aleatória e compulsiva. Podemos perceber a quantidade de estímulos concomitantes quando Rodrigo García descreve o processo da última obra do grupo que esteve no Brasil, chamada 4:

$\mathrm{Na}$ obra que estou ensaiando agora, essa que se chama 4, estou tentando criar um universo mais de movimentos e de objetos. [...] Compramos toca-discos de vinis, então estamos ensaiando. Os atores fazem movimentos, testam ruídos como êuêuê, fazemos como uma partitura musical e física com os toca-discos. E isso para mim é um material muito

2 Em A cinética do invisível, na análise dos processos criativos da companhia de Peter Brook, há a definição de improvisação enquanto método, diferenciando-a de um tipo de improvisação que está a serviço dos materiais cênicos, definida por "improvisação como instrumento" (BONFITTO, 2009). 
importante. Estamos trabalhando também com pequenos chocalhos nas roupas e estão fazendo movimentos... São coisas sonoras. Sigo trabalhando com animais e agora estamos trabalhando com galos. Compramos sapatilhas, dessas de correr, para crianças, e estamos pondo nos galos. É muito divertido. Há também um drone com uma câmera de vídeo. $\mathrm{E}$ estou trabalhando com uma pessoa que meteu uma espécie de campainhas que fazem tilin tilin tilin, fazem ruídos, então estou trabaIhando agora com coisas muito sonoras ${ }^{3}$.

Dessa forma, o período mais longo dos processos de criação se dá nesse trabalho improvisacional com as materialidades da cena, gerando inúmeros quadros que serão ordenados pelo encenador e propostos, em uma formatação mais próxima a que se tornará a obra, poucos dias antes da estreia. No entanto, é a partir da multiplicidade de estímulos, que percorre todo o processo de criação, que se constrói a busca por gerar certa instabilidade e propor um estado de presença constante nos atuantes. Os cenários, por exemplo, não se constroem como ambientações, mas como dispositivos cênicos capazes de estimular estados psicofísicos nos atores.

Manter um ator cozinhando, preocupado que não queime o azeite, me dá um efeito de realidade e liberdade, porque o ator está tão preocupado em sua ação real de cozinhar, nessa realidade do que está fazendo, que já não tem que preocupar-se com interpretar, simplesmente tem que fritar um ovo, se preocupar com fazer a carne... (DIAGO, 2002, p. 4. tradução dos autores).

Artifício de encenação que desloca a atuação, retirando-a de um estado meramente representacional, o cenário real da cozinha da obra Notas de cocina exige do ator atenção e prontidão em cena. Instaura uma perspectiva de jogo que restitui aos objetos seu uso comum. Propicia uma ação cênica que favorece o estado de presença propondo corporeidades distintas e conflitantes, em constante fricção com os demais elementos da cena (texto, música, iluminação), que remetem mais diretamente a um plano ficcional da obra. Desestabiliza a relação com o tempo ao possibilitar a coexistência cênica de um tempo ficcional, um tempo cronológico e o tempo da experiência.

3 Rodrigo García em entrevista concedida à pesquisadora Camila Damasceno em 26 de setembro de 2015, em Bogotá, Colômbia, e ainda não publicada. 
Essa permanente fricção entre os aspectos semânticos e não semânticos da cena são forte marca do trabalho do grupo espanhol. O caráter performativo dos processos de criação revela uma composição cênica que busca gerar estratégias que garantam um constante estado de atenção específica do ator. A relação que se estabelece com as materialidades, a fragmentação, a criação de quadros autônomos e o permanente descompasso entre ação e discurso parece fazer parte desse possível conjunto de estratégias que buscam sustentar um estado de presença intenso.

\section{Corporeidades performativas}

Para Erika Fischer-Lichte, a tensão entre "ter" um corpo e "ser" um corpo é o que possibilita a geração de corporeidades e uma percepção específica do público de tais corporeidades em cena. O corpo que nunca é, mas "está sendo" no mundo. Assim, ambos, gerar e perceber a corporeidade, dependem não somente do fenômeno da presença, mas também dos processos de corporificação (FISHER-LICHTE, 2008, tradução dos autores).

Em permanente transformação, engajado neste processo de "estar-sendo-no-mundo," portador de uma capacidade afetiva e energética, o corpo aqui é visto, então, como capaz de corporificar signos, movimentos, vozes, sons... No entanto, sua materialidade é específica. Organismo vivo, é capaz de funcionar como objeto, sujeito, material e fonte de construção simbólica, assim como produto de inscrições culturais (Ibid.).

No caso do La Carnicería, mais do que um estado de atenção, as corporeidades que se presentificam carregam uma atitude cênica, "um modo físico de estar em cena no qual se destaca a atitude de exposição e relação frente ao outro" (CORNAGO, 2008, p. 64, tradução dos autores). Exposição de um eu-ator/atriz que se constitui também de aspectos éticos e políticos, além de físicos e sensíveis. Para Óscar Cornago, as obras performativas contemporâneas põem em cena uma atitude ética pessoal dos artistas, que se posicionam enquanto criadores, considerando sua relação com um entorno social e político.

Se já não se trata da construção de um personagem de ficção, contudo, se busca a expressão de uma atitude, de uma determinada maneira de estar (em cena), um personagem/lugar cênico que implica um modo de relacionar-se 
com o outro, de posicionar-se frente ao mundo exterior. Isso implica em uma pesquisa de um tipo de comunicação que funciona em uma relação de proximidade, uma relação de verdade que passa pelo imediato, pela confrontação e pelo cara a cara com o público (Ibid., p. 52, tradução dos autores).

Diante do olhar do outro, a comunicação cênica constrói-se como sistema de tensões e instabilidades entre a representação e a experiência, entre a construção formal de um discurso, feito não somente por palavras, mas também por ações e corpos; e um evento (também feito por ações, corpos e palavras), a partir do encontro das sensibilidades, da copresença física de atores e espectadores que funda o fazer teatral. A cena é convertida em um espaço construído para possibilitar esse encontro com o outro. O olhar do público é de quem espera que algo aconteça, mas "o que acontece são os próprios corpos, que saem para a cena deixando seu testemunho desse passar pela vida e pelos cenários, de um compromisso, uma atitude crítica ou simplesmente um estar-aí" (Ibid.).

Em quase todos os espetáculos do La Carnicería, existem momentos de suspensão, nos quais os corpos se entrelaçam, se tocam, se despem, sem realizar uma ação que tenha como fim ativar qualquer tipo de relação interpretativa com a obra. Momentos autorreferenciais de exposição dessas corporeidades que parecem nos dizer mais do que "esses são atores", mas que "esses são corpos" físicos, materiais, sensíveis, se deslocando no espaço da cena, desnudando-se e profanando-se lentamente. "São corpos que perdem seu valor humano para transformar-se em matéria orgânica [...]. Corpos que se integram a imagens desumanizadas e [...] terrivelmente patéticas" (MONLEÓN, 2002, tradução dos autores), corpos em movimentos que dão a ver sua condição de vulnerabilidade sem psicologismos ou vitimizações na construção de corporeidades cheias de carne, fluidos e vozes.

Esses momentos específicos nas obras propõem quebras, descontinuidades, desestabilizações sensoriais, mantendo o espectador em uma espécie de suspensão entre duas ordens de percepção. Corporeidades que performam sobre a linha tênue entre representação e "presentação", que se deslocam continuamente em um lugar/estado liminar. "[...] para ir do corpo à carne, isto é, do corpo-objeto ao próprio corpo, vivido, parece muitas vezes necessário passar pela carne do açougueiro [...] é, muitas vezes, indispensável instá-lo até o limite" (DE MARINIS, 2012). 
A reflexão do pesquisador italiano Marco De Marinis, no entanto, parte das relações com o corpo que a bodyart estabelece, tratando de limites para além dos alcançados pelos atores do Carnicería, limites de autoflagelação real e modificações corporais definitivas. Mas a ideia de um corpo que é carne posta em exposição como "carne pronta para o consumo" não deixa de ser uma metáfora inspiradora para a análise dos processos de atuação do grupo, no qual a busca por um lugar limite se estabelece como um acordo tácito entre atores e encenador.

Durante o trabalho, tem um nível muito exigente, é como estar no precipício. Ele [García] não fala isso, mas eu sei que sempre quer que não nos acomodemos. Então é difícil, é muito trabalhoso, porque precisa estar sempre aí no limite da loucura ${ }^{4}$.

À beira do precipício, aqui, não é um lugar somente físico ou psicológico, nem tão pouco uma metáfora exagerada. Diz respeito a uma intensidade de presença e, ao mesmo tempo, a um condicionamento físico capaz de dar vazão às propostas de esgotamento, de ir aos limites reais do corpo. Uma ideia de liminaridade que instaura um modo de estar, uma qualidade de relação e presença, que subtrai os corpos "para a esfera do simbólico, por um lado, e para o formal, por outro", devolvendo-os à sua materialidade (Ibid.). Um espaço do entre, como propõe Victor Turner, um intermédio no qual o sujeito carrega características ambíguas, escapando de classificações que determinem com precisão seu lugar no processo cultural que se estabelece: "Os sujeitos em condições liminares não estão nem aqui nem lá, estão no meio" (1974). Encontrando-se nesse lugar limite, a cena propõe uma desestabilização sensorial capaz de fazer que os espectadores também experimentem, ao encontrarem-se na transição de uma ordem de percepção à outra, um estado liminar. A multiestabilidade perceptiva garante que nem "representação", nem "presença", estabilizem-se permanentemente. "Em turnos, a dinâmica do processo perceptivo sofre uma nova virada, criando cada vez mais instâncias de desestabilização" (FISCHER-LICHTE, 2008, tradução dos autores).

4 Juan Loriente em entrevista concedida à pesquisadora Camila Damasceno em 26 de setembro de 2015, em Bogotá, Colômbia, e ainda não publicada. 
Esse modo de estar no limite, instigado nos atores do grupo, transborda os momentos de atuação se disseminando pelos próprios processos de criação de cada obra. Mesmo diante de estratégias que parecem fomentar uma atitude de "se pôr em jogo" permanentemente, cabe aos atores elaborarem seus caminhos e preparações para alcançar e se manter nesse lugar fronteiriço que o trabalho do grupo propõe.

Individualmente, cada ator desenvolve seus modos próprios de preparação, mas o fim que buscam é sempre o mesmo: um estado de presença real e intenso, no qual disponibilidade e atenção estão latentes, em uma cena que se propõe enquanto espaço de distensão, de embate e de encontro com o outro, tanto dos demais atores, quanto o outro animal ou objeto e com o outro do espectador. Um espaço de efetivo estabelecimento de relações com as coisas do mundo a partir de suas materialidades, corporeidades e dos sentidos, das interpretações, construindo, assim, uma camada de superfície "onde se inscrevem os afetos, emoções e energias produzidas na cena" (CORNAGO, 2010, p. 375, tradução dos autores) concomitantemente a uma camada semântica, carregada por um discurso de crítica a um modelo econômico, político e social predominante nos países ocidentais. A flutuação perceptiva que a cena do Carnicería propõe aos espectadores passa principalmente por gerar e manter a mesma flutuação nos atores.

[...] em Cowboys, estamos quarenta minutos, só Juan e eu, em êxtase corporal. Buscamos realmente quase uma transcendência do corpo. Como uma loucura, sabe? E depois trocamos de roupa e nos vestimos de cowboys e começamos a dizer os textos tranquilamente, calmos. Vou escutando o que o Juan está dizendo, sem me preocupar com o que eu tenho que falar na sequência, dando valor a escutar o Juan. E é tão forte, que é uma obra que precisamos ter muito cuidado para que a cabeça não vá embora. Porque às vezes eu faço um texto, mas estou ouvindo o que ele está falando tão concentrado que fico como... E demoro a começar a falar. É uma obra que leva a esse limite do corpo, do furor do corpo e depois da palavra 5 .

Para os integrantes do grupo espanhol, gerar uma multiestabilidade perceptiva no público é consequência do fazê-la acontecer de fato na cena. Uma

5 Juan Loriente em entrevista concedida à pesquisadora Camila Damasceno em 26 de setembro de 2015, em Bogotá, Colômbia, e ainda não publicada. 
cena onde os corpos estão expostos, abertos, rasgados, virados e revirados sobre um cenário nunca composto para gerar ilusão nos espectadores. Carne, pelos, unhas e vozes. Viscerais. Extremos. "Vidas em sentido orgânico", literalmente realizando ações; corpos que projetam identidades físicas, que "são emoções e afetos, sentimento e companhia" (CORNAGO, 2007, p. 90), postura ética e política, corpos materiais e, ao mesmo tempo, carregados de signos. Corpos filmados em quadros fechados, projetados em telas imensas. Expostos em sua nudez, levados à exaustão, cobertos de mel, tinta e carne moída, banhados em leite e em argila, maltratados, estapeando-se mutuamente, revirando-se ou amarrando-se a objetos e alimentos. Corpos vivos e presentes, "materialidades da própria existência" (PLESSNER apud FISCHER-LICHTE, 2008, tradução dos autores), que a partir do encontro com o outro, da copresença física de atores e espectadores, impulsiona um sistema de tensões e instabilidades entre a representação e a presença, entre a construção formal de um discurso e o estabelecimento de um evento. Corporeidades que nos permitem perceber e sentir suas presenças para além de interpretá-las.

\section{Dramaturgia performativa e produção de corporeidlades}

A escolha de Rodrigo García por começar os processos a partir dos materiais e dos corpos inaugura um lugar de desestabilização de um aspecto meramente interpretativo muito presente em nosso cotidiano, deslocando as sensibilidades e propondo um modo de operar que considera a realidade física das coisas do mundo, buscando potencializar as possibilidades de acessar a sensibilidade do espectador por meio do que é material, palpável. O pressuposto de que é necessário que uma relação de fato se estabeleça em cena para que seja notada pelo público está presente em cada ensaio, em cada encontro, em cada apresentação, mesmo que não existam momentos "oficiais" de compartiIhamento dessas experiências e o dramaturgo insista em não discutir o que se faz, a fim de preservar uma camada tácita de percepção e compreensão.

A dupla condição de García de dramaturgo e encenador gera questões a respeito do desenvolvimento de certas competências que envolvem um fazer dramatúrgico inscrito em um processo de criação performativo. Uma perspectiva total da cena parece ser a primeira delas. A segunda, a capacidade de 
ordenar fragmentos considerando não somente um encadeamento que gere sentidos, mas também as possibilidades de sucessões de estímulos sensoriais e as fricções possíveis entre todas as materialidades cênicas, desde os corpos dos atores até objetos, luzes, sons, espaços e textos. A terceira, a exploração da materialidade das palavras no espaço e nos sons a partir de imagens e vozes.

Os processos de criação aqui descritos dão a ver uma atuação do dramaturgo como um arquiteto de materialidades, estimulando a criação dos atores a partir de múltiplos disparadores. A construção de uma dramaturgia performativa parece então passar por uma atitude de García que não se detém à criação de um texto para a cena ou de uma "ideia de encenação", mas trabalha principalmente no desenvolvimento de uma escritura "cênico-dramatúrgica", como afirma José Da Costa, que "diz respeito a um campo de mediações intertextuais, intertemporais, intersemióticas, interartísticas e/ou intermídias" (DA COSTA, 2009), a qual eu acrescentaria ainda intercorporais e intermateriais.

Essa mediação não se revela, no entanto, como busca por um apaziguamento ou equilíbrio das relações. Pelo contrário, movimenta um sistema de tensões e resistências "que acentua a dimensão performativa, o trabalho com as materialidades [...], o sentido processual da obra, seu caráter de imediatez, a comunicação sensorial com o público e o sentido de coletividade" (CORNAGO, 2006, p. 171, tradução dos autores).

A busca por uma desestabilização sensorial do espectador impulsiona a exploração de múltiplos dispositivos capazes de gerar primeiramente uma desestabilização nos próprios atores. A fricção entre momentos que exploram principalmente a construção de sentidos e de interpretações diante de um discurso e momentos mais autorreferenciais que, por sua vez, exploram as materialidades (corpos, objetos, sons, luzes, espaços) gera um fluxo contínuo de criação de corporeidades que flutuam através da construção de seres ficcionais distintos, levando os atores a uma tentativa permanente de equilibrarem-se sobre a linha tênue que separa seu "ser no mundo" do seu "ser na cena." Equilíbrio utópico que os impulsiona à "beira do abismo", mantendo uma tensão permanente que contamina a atmosfera da cena do La Carnicería, gerando uma multiestabilidade perceptiva que atinge o público em cheio. 


\section{Referências bibliográficas}

BONFITTO, M. A cinética do invisível. São Paulo: Perspectiva, 2009.

CDN (Centro Dramático Nacional). Entrevista con el director. Cuaderno Pedagogico, 51, Madrid, p. 9-17, 2010.

CORNAGO, O. Teátrica pagã: diálogos de Jean-François Lyotard com a cena. Sala Preta, São Paulo, n. 10, p. 371-381, 2010. Disponível em: < http://www.revistas. usp.br/salapreta/article/view/57418>.

Cuerpos, politica y sociedad: una cuestión de ética. In: Éticas del cuerpo. Juan Domínguez, Marta Galán, Fernando Renjifo. Madrid: Fundamentos, 2008, p. 50-83.

¿En qué piensa Europa? Acerca de Accidens, de Rodrigo García, Afuera: Estudios de Crítica Cultural, $n^{\circ} 3$, nov. 2007.

Teatro postdramático: las resistencias de la representación. In: SÁNCHEZ,

J. A. (Dir.). Artes de la escena y de la acción em España 1978-2002. Cuenca: UCLM, 2006. p.165-179.

DA COSTA, J. Teatro contemporâneo no Brasil: criações partilhadas e presença diferida. Rio de Janeiro: 7 Letras, 2009.

DE MARINIS, M. Corpo e corporeidade no teatro: da semiótica às neurociências.

Pequeno glossário interdisciplinar. Revista Brasileira de Estudos da Presença, Porto Alegre, v. 2, n. 1, p. 42-61, jan./jun, 2012.

DIAGO, N. Conversando com Rodrigo García. Los limites del teatro. El teatro y sus limites. Stichomythia: revista de teatro español contemporáneo, 2002. Disponível em: <http://parnaseo.uv.es/Ars/ESTICOMITIA/Numero0/indicecero/a8.htm>. Acesso em: 13 ago. 2014.

FISCHER-LICHTE, E. The transformative power of performance: a new aesthetics. London: Routledge, 2008.

GARCÍA, R. Rodrigo García e John Romão (Carnicería Teatro/ Gólgota Picnic). MITsp, vídeo de 1h04, 2014. Disponível em: <https://www.youtube.com/watch?v=1gxjtHIOOIA>. Acesso em: 15 jan. 2015.

Cenizas escogidas. Segóvia: La Uña Rota, 2013.

KANTOR, T. O teatro da morte. São Paulo: Perspectiva, 2008.

MONLÉON, J. Teatro de profanación, Primer acto, n. 294, p. 67-70, 2002.

TURNER, V. O processo ritual. Petrópolis: Vozes, 1974.

Recebido em 11/03/2017

Aprovado em 22/05/2017

Publicado em 14/07/2017 